\title{
PENGARUH LATIHAN KELENTUKAN STATIS \\ TERHADAP SENAM LANTAI FORWARD ROLL PADA ATLET USIA DINI EXSTUDIO BODY SHAPE CENTER PALEMBANG
}

\author{
Sugarwanto $^{1)}$, Ardo Okilanda ${ }^{2)}$ \\ 1, Universitas PGRI Palembang \\ ${ }^{2}$ Universitas PGRI Palembang \\ sugar.wanto88@gmail.com ${ }^{1}$, ardo.oku@gmail.com ${ }^{2}$
}

\begin{abstract}
Abstrak
Tujuan penelitian ini adalah untuk mengetahui seberapa besar pengaruh latihan kelentukan statis terhadap senam lantai forward roll atlet usia dini exstudio body shape center palembang. Metode penelitian yang digunakan metode eksperimen model one group pretest-posttest. Populasi dalam penelitian ini adalah semua atlet usia dini exstudio body shape center yang berjumlah 41 atlet didapat dari dua kali hasil tes terhadap subjek penelitian, yaitu tes awal (pretest) dan tes akhir (posttest), bentuk tes yang dilaksanakan yaitu instrument tes forward roll. Teknik analisis data yang digunakan adalah menggunakan teknik statistik deskriptif model distribusi frekuensi, uji normalitas data, dan uji hipotesis yang berpedoman pada rumus uji t. Berdasarkan hasil analisis terhadap semua data yang terkumpul, dapat disimpulkan bahwa ada pengaruh latihan kelentukan statis terhadap senam lantai forward roll pada atlet usia dini exstudio body shape center palembang. Pernyataan tersebut dapat dibuktikan dengan melihat dan membandingkan nilai rata-rata hasil tes awal (pretest) yaitu 54,02 dengan nilai rata-rata hasil tes akhir (posttest) yaitu 74,5. Selain itu juga didukung oleh hasil uji hipotesis terhadap data pretest dan posttest dimana didapat $t_{\text {hitung }}(20,04)>t_{\text {tabel }}(2,02)$. Sesuai dengan kriteria pengujian hipotesis yang telah dirumuskan, dimana jika $t_{\text {hitung }}>t_{\text {tabel }}$ maka terima hipotesis yang menyatakan bahwa ada pengaruh latihan kelentukan statis terhadap senam lantai forward roll pada atlet usia dini exstudio body shape center Palembang.
\end{abstract}

Kata Kunci: Kelentukan Statis, Forward Roll, Usia Dini

\section{Abstract}

The objective of the study determined how much influence the exercise of static flexibility on the forward roll floor gymnastics of early athlete in Exstudio body shape center of Palembang. Method of this study was used experimental of one group pretest-posttest model. The populations were all 41 young athletes of Exstudio body shape center obtained from twice tests, namely the initial test (pretest) and final test (posttest), the form of the test carried out was the forward roll test instrument. The data analysis technique used is descriptive statistical technique of frequency distribution models, data normality test, and hypothesis testing based on the t-test formula. The result shown there is an effect of static flexibility exercises on the forward roll floor gymnastics in early athlete of Exstudio body shape center Palembang. The statement can be proven by observing and comparing the average value of the initial test results (pretest) which is 54.02 with the average value of the final test results (posttest) that is 74.5. It is supported by the results of hypothesis testing of the pretest and posttest data where $t_{\text {count }}$ (20.04)> $t_{\text {table }}$ (2.02) is obtained. In accordance with the hypothesis testing criteria was formulated, where if $t_{\text {count }}>t_{\text {table }}$ then accept the hypothesis which states that there is an effect of static flexibility exercises on the forward roll floor gymnastics in early age athletes of Exstudio body shape center Palembang. 


\section{Pendahuluan}

Olahraga di masyarakat tidak hanya untuk kepentingan pendidikan, rekreasi dan kesegaran jasmani, tetapi juga sebagai ajang prestasi (Okilanda, 2017).Senam terdiri dari gerakangerakan yang luas/banyak atau menyeluruh dari latihan-latihan yang dapat membangun atau membentuk otot-otot tubuh seperti, pergelangan tangan, punggung, lengan dan lain sebagainya. Senam atau latihan tersebut termasuk juga didalamnya unsur-unsur jungkir balik, lompatan, memanjat dan keseimbangan. Sebelum memberikan latihan gerakan dasar (elemen) pada anak-anak perlu adanya pembinaan dan pembentukan fisik yang teratur, hal ini perlu karena dengan adanya fisik yang sudah terbentuk (kekuatan, kelemasan, kelentukan, keterampilan, koordinasi otot-otot dan lain-lain) akan memudahkan dalam mempelajari gerakan-gerakan dasar (elemen) senam. "Senam adalah sebuah latihan tubuh yang dipilih dan dikonstruk dengan sengaja, dilakukan secara sadar dan terencana, disusun secara sistematis dengan tujuan meningkatkan kesegaran jasmani, mengembangkan keterampilan dan menanamkan nilainilai mental spiritual"(Hidayat,1996).

Senam telah dilakukan oleh manusia karena berkaitan dengan aktifitas manusia. Dari kepingan batu purba dizaman Mesir kuno sekitar 3000 tahun Sebelum Masehi telah menggambarkan aktivitas akrobatik. Seribu tahun setelah itu, orang-orang di Cina mengembangkan senam dengan sebutan Cong Fu. Senam pada saat itu lebih kepada gerakan-gerakan akrobatik yang ditampilkan seni pertunjukan.
Senam dipertandingkan saat Olimpiade pertama kali di Yunani tahun 1896. Saat itu persertanya hanya laki-laki. Senam untuk wanita dipertandingan mulai Olimpiade tahun 1928.Senam artistik di Indonesia hadir menjelang Pesta Olahraga Ganefo I di Jakarta pada tahun 1963. Pada event itu, senam merupakan salah satu cabang olahraga yang dipertandingkan. PERSANI (Persatuan Senam Indonesia) dibentuk pada tanggal 14 Juli 1963 (Aksara,2008:39).

Senam lantai merupakan salah satu bagian disiplin cabang olahraga senam artistik. Selain itu, senam lantai ini juga merupakan cabang olahraga yang sangat menarik. Kebanyakan orang ingin memiliki kemampuan salto (berguling di udara) dan banyak gerakan-gerakan lain yang mereka inginkan, namun mereka belum tahu bagaimana cara dan dimana berlatihnya. Terkadang mereka hanya melihat dari pertunjukan akrobatik atau atraksi sirkus di televisi, sudah langsung ingin mencoba gerakan tersebut. Mereka tidak menyadari bahwa gerakan yang mereka lakukan sangat berbahaya. Apalagi bila mereka mencoba gerakan salto (berguling di udara), tanpa perhitungan bahwa gerakan tersebut sebelumnya harus dipelajari melalui tahapan-tahapan latihan yang berjenjang dan berkesinambungan. Tidak mungkin mereka langsung dapat melakukan gerakan tersebut dalam waktu yang singkat. Selain itu proses latihan diperlukan pemantauan dan arahan seorang pelatih yang berpengamalan ,serta ditunjang dengan saran dan prasarana yang memenuhi syarat. senam lantai adalah olahraga menarik tetapi sangat rentan terjadinya cedera, 
untuk mengurangi resiko terjadinya cedera dengan cara latihan, salah satu latiahannya ialah latihan kelentuakan.

Gerakan senam lantai terdiri 3 langkah yaitu 1) sikap awal; 2) gerakan mengguling; dan 3) sikap akhir (Aka, 2009). Masing-masing tahap dilakukan secara berkelanjutan dan tidak terputus hingga akhirnya sampai pada penyelesaian gerakan. Gerakan ini didukung oleh kelentukan tubuh yang baik agar dapat badan terlihat seperti terlipat. Senam dapat diartikan sebagai setiap bentuk latihan fisik yang tersusun secara sistematis dengan melibatkan gerakan-gerakan yang terpilih dan terencana untuk mencapai tujuan tertentu (Martiani, 2018).

Tangkudung dan Puspitorini (2006), "Kelentukan adalah kemampuan untuk melakukan gerakan persendian melalui jangkauan gerak yang luas". Lentuk atau tidaknya seseorang tidak ditentukan oleh postur tubuhnya melainkan karena seringnya berlatih. Pendapat ini juga didukung oleh (Widiastuti, 2011), "Kelentukan adalah kemampuan sendi untuk melakukan gerakan dalam ruang gerak sendi secara maksimal". Maksimalnya sendi sendiri didorong oleh faktor tekanan yang membiasakan tubuh untuk mengatasi tahanan, sehingga akhirnya bisa digerakkan secara luas.

Roll (berguling) adalah aktivitas gerak tubuh dengan membulatkan badan sedemikian rupa sehingga badan berguling ke arah sisi yang lain (Aka, 2009). John and Mary (2008) menjelaskan cara melakukan roll ke depan dimulai dengan posisi jongkok, tangan diangkat lurus ke atas sehingga badan lurus dari pinggul hingga ujung jari tangan. Angkatlah pinggul dan pindahkan berat badan ke depan, letakkan kedua tangan anda pada matras. Sentuhkan dagu ke dada, letakkan bahu diatas matras sambil berguling, Jagalah agar badan tetap menekuk dengan kedua lutut tetap di dada dan akhirilah dengan sikap jongkok dengan kedua tangan lurus ke atas.

Forward Roll adalah gerakan berguling ke depan yang diawali dengan sikap jongok kaki rapat, letakan telapak tangan ke depan (jarak antara kaki dan tangan sama dengan jarak kaki dan lutut dalam sikap merangkak), luruskan kaki hingga panggul terangkat lalu condongkan badan ke depan kepala masuk diantara tangan, bengkokkan tangan dan letakan punggung dilantai, badan membundar, akhirilah dengan sikap jongkok dengan kedua tangan lurus diatas. Inti dari gerakan guling depan terletak pada tolakan kaki dan sikap badan 12 ke depan (Ruslan dan Huda, 2019). Berdasarkan pendapat para ahli tersebut dapat simpulkan bahwa roll ke depan adalah aktivitas menolak atau tolakkan tubuh ke arah depan. Tangan dibengkokkan, kaki tetap dirapakant, gerakan dapat diawali dengan sikap jongkok dan diakhiri dengan sikap jongkok.

Latihan (training) menurut Kosasih (1993) ialah proses kerja yang harus dilakukan secara sistematis, berulangulang dan jumlah beban yang diberikan semakin hari bertambah. Sedangkan (Sukadiyanto 2011) menjelaskan latihan adalah proses perubahan kemampuan kea rah yang lebih baik, tujuannya meningkatkan kualitas fisik, kemampuan fungsional alat tubuh dan kualitas psikologi atlet.

(Harsono, 1988), menyatakan bahwa tujuan dari latihan atau training ini adalah untuk membantu atlet meningkatkan keterampilan dan prestasinya semaksimal mungkin. Untuk mencapai hal itu ada empat 
aspek latihan yang perlu diperhatikan dan dilatih secara maksimal oleh atlet yaitu latihan fisik, latihan teknik, latihan taktik dan latihan mental.

Kelentukan sebagai salah satu komponen kesegaran jasmani merupakan kemampuan menggerakan tubuh atau bagian-bagianya seluas mungkin tanpa terjadi ketegangan sendi cedera otot. (Davis 2008) kelentukan seseorang dipengaruhi oleh: tipe persendian, panjang istirahat otot, panjang istirahat ligamen dan kapsul sendi, bentuk tubuh, temperatur otot, jenis kelamin, usia, ketahanan kulit,dan bentuk tulang. Faktor-faktor yang mempengaruhi kelentukan tersebut oleh: keturunan, sejumlah faktor lingkungan misalnya latihan, pemanasan temperatur.

Kelentukan adalah kemampuan untuk bergerak dalam ruang gerak sendi. Dalam olahraga, kalu kiat bicara mengenai kelentukan (flexibility), kita biasanya mengacu pada ruang gerak sendi tubuh. Lentuk- tidaknya seseorang ditentukan luas-sempitnya ruang gerak sendi-sendinya. Kecuali oleh ruang sendi, kelentuakan juga ditentukan oleh elastic tidaknya otototot, tendon, daan ligamen disekitar sendi Harsono dalam Rosdiani (2012) Orang yang memiliki kelentukan adalah orang yang mempunyai ruang gerak yang luas dalam sendi-sendinya dan mempunyai otot-otot yang elastis. Kelentukan (flexibility) adalah kemempuan untuk menggerakan otot berserta persendian pada seluruh daerah pergerakan (Alter 2004). Latihan kelentukan dalam penelitian ini yaitu dengan latihan peregangan statis, peregangan statis dilakukan dengan tahanan bagi atlit.

Berdasarkan hasil pengamatan peneliti pada saat mengadakan studi pendahuluan di exstudio body shape center palembang, rata-rata gerakan roll ke depan para atlet tidak didukung oleh kelentukan yang baik dan terindikasi hampir seluruh atlet dalam melakukan roll ke depan tidak dengan kelentukan yang baik. Kenyataan tersebut membuat peneliti tertarik untuk mengadakan riset lebih mendalam dan mendeskripsikan penelitian ini dengan judul, "Pengaruh Latihan Kelentukan Statis terhadap Senam Lantai Roll kedepan pada Atlet usia dini exstudio body shape center palembang."

\section{BAHAN DAN \\ METODE/METODOLOGI}

Penelitian menggunakan desain penelitian model one-group pretestposttest design (Winarno, 2007) yang melibatkan satu kelompok dan dilakukan pretest (tes awal), kemudian diberikan suatu perlakuan (treatment) selama 16 kali pertemuan, dan selanjutnya dilakukan posttest (tes akhir) dengan jadwal Januari-Februari 2020. Populasi dalam penelitian ini adalah atlet usia dini exstudio body shape center palembang yang berjumlah 95 orang. Adapun teknik pengambilan sampel pada penelitian ini menggunakan teknik simple random sampling dimana pengambilan anggota sampel dari populasi dilakukan secara acak tanpa memperhatikan strata yang ada dalam populasi itu. Sampel yang digunakan pada penelitian ini adalah semua atlet putra-putri usia dini exstudio body shape center palembang berjumlah 41 orang. Untuk mengolah data hasil tes awal (pretest) dan tes akhir (posttest) dalam penelitian ini, maka digunakan langkah-langkah statistik yang berpedoman pada rumus uji " $t$ ". 


\section{Hasil dan PeMbahasan}

Berdasarkan hasil pelaksanaan tes awal (pretest) roll ke depan yang dilaksanakan, didapat data yang selanjutnya disebut data awal atau data hasil pretest. Adapun data hasil tes awal (pretest) mempunyai skor tertinggi 75 dan skor terendah 40, dengan jumlah skor keseluruhan 2215 dan skor rata-rata 54,02.

Tes akhir (posttest), setelah semua atlet diberi perlakuan (treatment) yaitu berupa latihan kelentukan statisselamasatu bulan. Setelah tes akhir (posttest) dilaksanakan, maka didapat data yang selanjutnya disebut data hasil tes akhir (posttest) untuk kemudian diolah dan dianalisis. Adapun data hasil posttest mempunyai skor tertinggi 95 dan skor terendah 60, dengan jumlah skor keseluruhan 3055 dan skor rata-rata 74,5.

\begin{tabular}{ccccc} 
& Mean & $\mathrm{t}_{\text {hitung }}$ & $\mathrm{t}_{\text {tabel }}$ & Kesimpulan \\
\cline { 1 - 2 } Pretest & 54,03 & 20,04 & 2,02 & Signifikan \\
\cline { 1 - 2 } Postest & 74,5 & & & \\
\hline
\end{tabular}

Tabel 1. Roll ke depan Pretest dan

$$
\text { Posttest }
$$

Karena skor $t_{\text {hitung }}>t_{\text {tabel }}$ dan berdasarkan kriteria pengujian hipotesis, maka tolak $\mathrm{H}_{\mathrm{o}}$ yang menyatakan tidak ada pengaruh latihan kelentukan statisterhadaproll ke depan, dan terima $\mathrm{H}_{\mathrm{a}}$ yang menyatakan ada pengaruh latihan kelentukan statis terhadap roll ke depan.

Pada pelaksanaan tes awal (pretest) roll ke depan pada atlet usia dini exstudio body shape center palembang didapat skor tertinggi 75 dan skor terendah 40, dengan jumlah skor keseluruhan 2215 dan nilai rata-rata 54,02. Setelah dilakukan tes awal (pretest) kemudian semua subjek penelitian diberi perlakuan (treatment) yaitu berupa latihan kelentukan statis yang dilaksanakan selama 6 minggu. Setelah pelaksanaan pemberian perlakuan terhadap semua subjek penelitian, kemudian dilanjutkan pada tahapan tes akhir (posttest). Berdasarkan hasil pelaksanaan tes akhir (posttest), didapat hasil dengan skor tertinggi 95 dan skor terendah 60 , dengan jumlah skor keseluruhan 3055 dan nilai rata-rata 74,5 . Data yang didapat dari hasil tes awal (pretest) dan tes akhir (posttest) kemudian diolah dan dianalisis dengan terlebih dahulu melakukan uji normalitas data dan uji homogenitas. Setelah diketahui bahwa sebaran data adalah normal dan homogen, analisis data dapat dilanjutkan dengan melakukan pengujian hipotesis dengan berpedoman pada rumus uji $t$, dan didapat hasil $t_{\text {hitung }}=20,04$ dan $t_{\text {tabel }}=$ 2,02 (Arikunto, 2006).

\section{KESIMPUlan dAN SARAN}

Berdasarkan hasil penelitian dan pembahasan maka dapat disimpulkan bahwa terdapat pengaruh yang signifikan latihan kelentukan statis terhadap senam lantai roll ke depan pada atlet usia dini exstudio body shape center palembang, pernyataan tersebut dapat dibuktikan dengan melihat dan membandingkan nilai rata-rata hasil tes awal (pretest) yaitu 54,02 dengan nilai rata-rata hasil tes akhir (posttest) yaitu 74,5. Selain itu juga didukung oleh hasil uji hipotesis terhadap data pretest dan posttest dimana didapat $t_{\text {hitung }}(20,04)>$ $t_{\text {tabel }}(2,02)$. Sesuai dengan kriteria pengujian hipotesis yang telah dirumuskan, dimana jika $t_{\text {hitung }}>t_{\text {tabel }}$ maka terima hipotesis yang menyatakan bahwa ada pengaruh latihan kelentukan statis terhadap senam lantai roll ke depan pada atlet 
usia dini exstudio body shape center palembang.

Bagi Pembina cabang olahraga senam dan pelatih olahraga, sebagai bahan pertimbangan untuk memberikan bentuk/metode latihan yang baru agar dapat meningkatkan prestasi olahraga khususnya cabang senam lantai. Bagi atlet, agar lebih giat dalam berlatih untuk meningkatkan kemampuan teknik olahraga tidak hanya pada jam latihan, tetapi juga dapat mengikuti kegiatan di luar waktu latihan tentu dengan prinsip hati-hati karena latihan ini perlu ada pengawsan apalagi gerakan peregangan statis membuat otot berhenti dengan tekanan tinggi, untuk klub agar terus memperhatikan dan memberikan kesempatan kepada atlet untuk mengasah serta meningkatkan bakat olahraga yang mereka miliki dengan menambah jumlah jam pada program pengembangan diri dalam latihan. Bagi teman-teman insane olahraga, harapannya dapat mengembangkan penelitian yang serupa tetapi dengan pokok bahasan cabang-cabang olahraga lainnya.

\section{Daftar Pustaka}

Aka, Biasworo Adisuyanto. 2009. Cerdas Dan Bugar Dengan Senam Lantai. Grasindo.

Alter, Michael J. 2004. Science of Flexibility. Human Kinetics.

Arikunto, Suharsimi. 2006. "Penelitian Suatu Pendekatan Praktek." Jakarta: Rineka Cipta.

Davis, Shala E. 2008. ACSM's HealthRelated Physical Fitness Assessment Manual. Lippincott Williams \& Wilkins.

Harsono, M. Sc, and M. S. Drs. 1988. "Coaching Dan Aspek-Aspek Psikologis Dalam Coaching."
Direktorat Jendral Pendidikan Tinggi: Jakarta.

Hidayat, Imam. 1996. "Biomekanika." Bandug: FPOK-IKIP.

John, Mary Jean Traetta, and Jean Mary. 2008. Dasar-Dasar Senam. Bandung: Angkasa Bandung.

Kosasih, Engkos. 1993. "Olahraga Dan Program Latihan." Akademika Presindo. Jakarta.

Martiani, Martiani. 2018. "Pengaruh Penggunaan Metode Drill And Practice Dan Konsentrasi Terhadap Keterampilan Headstand Senam Ketangkasan." Altius: Jurnal Ilmu Olahraga Dan Kesehatan 7(1).

Okilanda, Ardo. 2017. "Analisis Pembelajaran Gerak Keterampilan Teknik Dribbling Ssb Imam Bonjol Padang." WAHANA DIDAKTIKA 15(3).

Rosdiani, Dini. 2012. "Dinamika Olahraga Dan Pengembangan Nilai." Bandung: Alfabeta.

Ruslan, Ruslan, and M. Samsul Huda. 2019. "Penerapan Metode Bermain Dalam Meningkatkan Hasil Belajar Guling Depan (Forward Roll)." Halaman Olahraga Nusantara (Jurnal Ilmu Keolahragaan) 2(1):10-20.

Sukadiyanto, Sukadiyanto. 2011. "Pengantar Teori Dan Metodologi Melatih Fisik." Yogyakarta: UNY Press.

Tangkudung, James, and Wahyuningtyas Puspitorini. 2006. "Kepelatihan Olahraga Pembinaan Prestasi Olahraga." Jakarta: Cerdas Jaya.

Widiastuti, Dr, and M. Pd. 2011. "Tes Dan Pengukuran Olahraga." Jakarta: PT. Bumi Timur Jaya.

Winarno, M. E. 2007. "Research Methodology in Physical 
Sport, Physical Education, Organization, Recreation, Training

Education." Malang: Faculty of

Education, Malang State

University. 